\title{
The Practitioner's Guide to Deep Mixing
}

\author{
Donald A. Bruce ${ }^{1}$ and Mary Ellen C. Bruce ${ }^{2}$
}

\begin{abstract}
The various techniques which constitute the Deep Mixing Method (DMM) are being used to treat, improve, and retain a variety of soil types on an international basis. A recent U.S. Federal research program has generated a detailed review of technology worldwide, and the broad findings of the research are presented in this paper. Major areas of focus are application, technology, and QA/QC and verification.
\end{abstract}

\section{Introduction}

The Deep Mixing Method (DMM) is an in situ soil treatment and improvement technology whereby the ground is blended with cementitious and/or other materials. These materials are internationally referred to as "binders" and can be introduced in slurry or dry form. They are injected through hollow, rotated mixing shafts tipped with some type of cutting tool. The shaft above the tool may be further equipped with discontinuous auger flights and/or mixing blades or paddles. These shafts are mounted vertically on a suitable carrier, usually crawler-mounted for work on land, and range in number from one to eight (typically two to four) per carrier, depending on the nature of the project, the particular variant of the method, and the contractor. Individual column diameters typically range from 0.6 to $1.5 \mathrm{~m}$, and may extend to $40 \mathrm{~m}$ in depth. In some methods, the mixing action is enhanced by simultaneously injecting fluid grout at high pressure through nozzles in the mixing or cutting tools.

The cemented material that is produced generally has a higher strength, lower permeability, and lower compressibility than the native ground, although total unit

\footnotetext{
${ }^{1}$ President, Geosystems, L.P., P.O. Box 237, Venetia, PA 15367, U.S.A., Telephone: (724) 942-0570; fax: (724) 942-1911; email: dabruce@geosystemsbruce.com. ${ }^{2}$ President, geotechnica, s.a., Inc., P.O. Box 178, Venetia, PA 15367, U.S.A., Telephone: (724) 942-4220; fax: (724) 942-1911; email: mebruce@cobweb.net.
} 
weight may be less. The exact properties obtained reflect the characteristics of the native soil, the construction variables (principally the mixing method), the operational parameters, and the binder characteristics.

Current practice is broadly based around Japanese and Scandinavian efforts dating from the late 1960s. In the United States, the works at Jackson Lake Dam, WY (late 1980s) (Ryan and Jasperse, 1989), Logan Airport, Boston, MA (early 1990s) (Nicholson and Chu, 1994), and Fort Point Channel, Boston, MA (late 1990s) (Das et al., 1998) have generated widespread industry interest and have established DMM as a technique of substantial technical merit and economic attractiveness, in favorable conditions.

Until 1997, DMM in the United States was virtually synonymous with two very similar, multishaft methods typically used for creating "walls" for structural support, seepage cut off and hazardous waste containment. These methods - "Deep Soil Mixing" (DSM) and "Soil Mixed Wall" (SMW) were actively and properly promoted in the technical press by their respective companies, namely GeoCon and Seiko. Despite similar marketing efforts from other companies with less resources and experience in the United States, there was a general unawareness of the wider range of technological options available to satisfy other geotechnical and structural applications. Indeed, it is common to still find engineers referring to DMM as SMW (a service mark), or DSM (an apt descriptor, but also having a proprietary origin) or some other variant such as DSCM (Deep Soil Cement Mixing)

From 1997 to 2000, therefore, the Federal Highway Administration (FHWA) funded the lead author to provide a detailed assessment of the whole field of DMM as related primarily to geotechnical applications. The publication of the resultant three volumes (in 2000 and 2001) and the various technical papers arising has helped to both stimulate and rationalize contemporary U.S. attitudes towards DMM, and has contributed to the wave of interested reflected in the formation of working groups and task forces (e.g., Deep Foundations Institute Committee; GeoInstitute Task Force), lecture courses and workshops, and, most recently, a National Research Program, funded by a consortium of individual States under the guidance of the FHWA.

It must be noted however, that there remain somewhat unresolved aspects to our current DMM practice (which it is hoped will be resolved by the National Research Program), which reflect a combination of ignorance and inexperience. For example, the whole issue of QA/QC, verification, and acceptance still remains of variable definition. The purpose of this short paper is simply to provide the (potential) practitioner with a basic guide to the technology as it stands in the U.S. at the beginning of the $21^{\text {st }}$ century. It is intended to provide basic "facts of life" and to act as a framework upon which the mass of information available from other sources - especially technical papers and/or the contractors themselves - can be rationalized and put in perspective. The paper covers the scope of the FHWA research and therefore focuses on applications, technology, properties, and verification.

\section{Application and Applicability}

The various DMM techniques can be used to produce a wide range of treated soil structures on both land and marine projects (Figure 1): 
- $\quad$ Single elements.

- Rows of overlapping elements (walls or panels).

- Grids or lattices.

- Blocks.

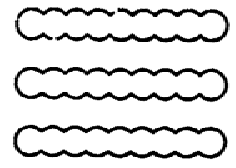

Woll Type

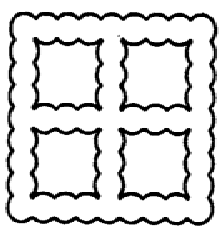

Grid Type

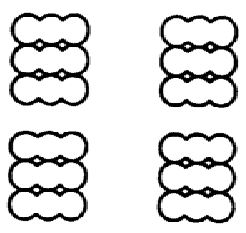

Block Type

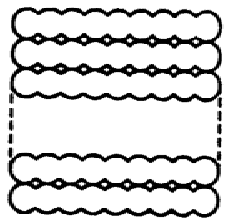

Areo Type

Basic Treatment Patterns on Land

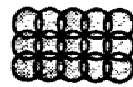

Block Type

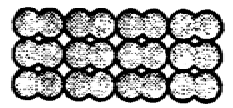

Tongent Column
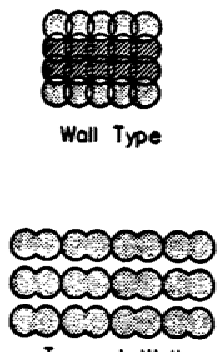

Tongent. Woll
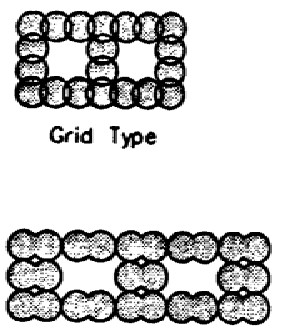

Tongent Grid
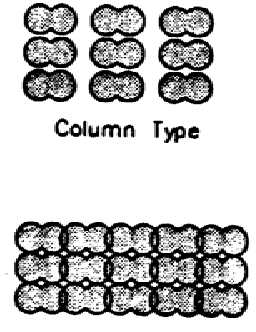

Tongent Block

\section{Basic Treatment Patterns in Marine Conditions}

Figure 1. Basic deep mixing treatment patterns (Yang, 1997)

(Note: Single columns are also produced by many of the DMM techniques.)

The particular geometry chosen is dictated by the purpose of the DMM application, and reflects the mechanical capabilities and characteristics of the particular method used. The main groups of applications are as follows, with the countries in parentheses indicating their international application:

- $\quad$ Hydraulic cut-off walls (Japan, U.S.).

- $\quad$ Excavation support walls (Japan, China, U.S.).

- $\quad$ Large volume ground treatment (Japan, China, U.S.).

- $\quad$ Liquefaction mitigation (Japan, U.S.).

- In situ reinforcement, piles, and gravity walls (Scandinavia, Western Europe)

- $\quad$ Environmental remediation (U.S., Western Europe).

A slightly more detailed classification was provided by Porbaha (1998), as shown in Figure 2. 
In the most general terms, DMM may be most attractive in projects where:

- the ground is neither very stiff nor very dense, nor contains boulders or other obstructions;

- $\quad$ treatment depths of less than about $40 \mathrm{~m}$ are required;

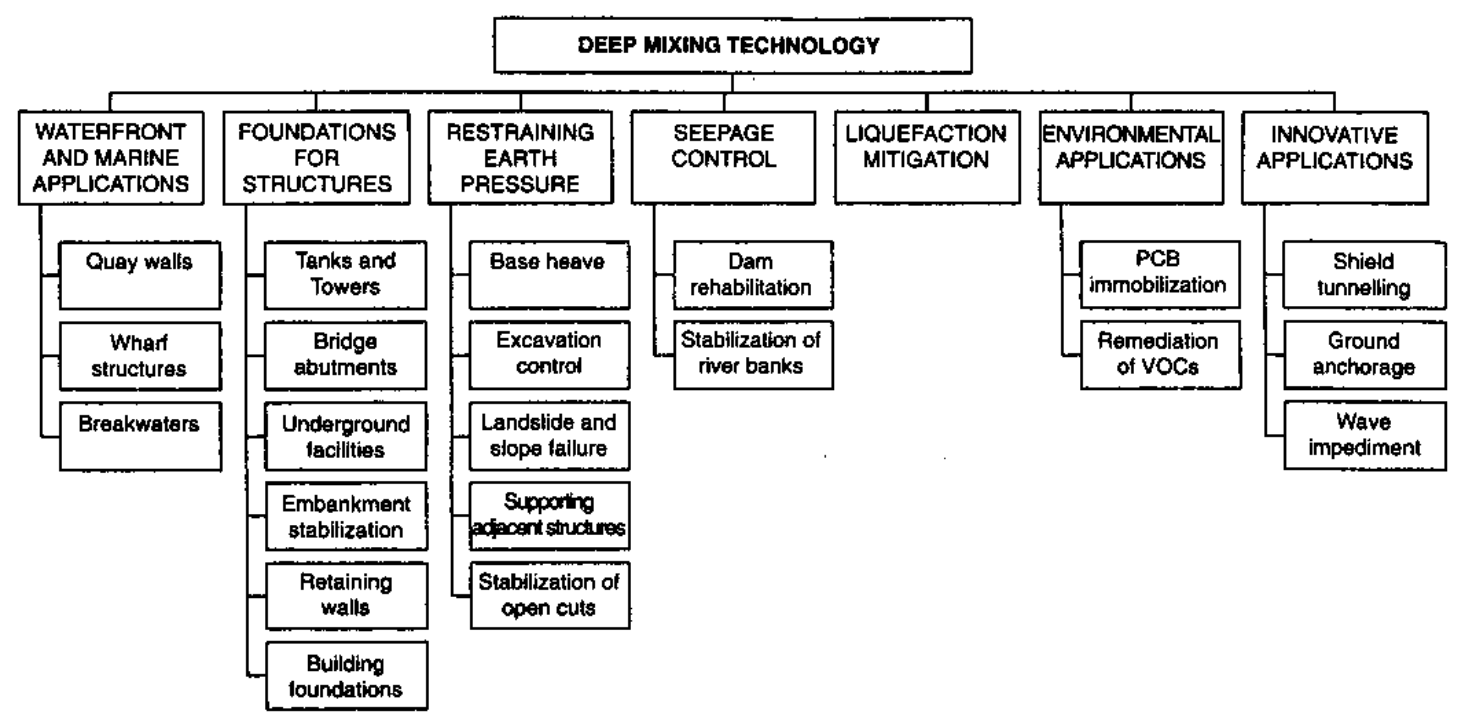

Figure 2. Proposed classification of DMM applications (Porbaha, 1998).

- $\quad$ there is relatively unrestricted overhead clearance;

- $\quad$ a constant and good supply of binder can be ensured;

- a significant amount of spoil can be tolerated;

- a relatively vibration-free technology is required;

- $\quad$ treated or improved ground volumes are large;

- "performance specifications" are applicable; or

- $\quad$ treated ground strengths have to be closely engineered (typically 0.1 to 5

$\mathrm{MPa}$ ).

Otherwise, and depending always on local conditions, it may prove to be more appropriate to use alternative ground treatment technologies such as jet grouting, diaphragm walling, sheet piling, caissons, beams and lagging, driven piles, wick drains, micropiles, soil nails, vibrodensification, lightweight fills, compaction grouting, deep dynamic consolidation, bioremediation, vapor extraction, or simply to remove and replace the native soil. 


\section{Technology}

\subsection{DMM Techniques}

While some DMM techniques are at the early developmental or field demonstration stages, the majority can be regarded as fully operational within certain geographic areas and trade groupings. For example, reflecting the huge amount of projects in Japan, each of the several major "trade associations," such as DJM, CDM, SMW, and SWING, have numerous licensed contractors, each with many rigs of different capacities. Elsewhere, the contractors are more widely distributed, but are principally based in Scandinavia, the United States, China, and France. These markets are not yet so large in volume as in Japan, and thus the contractors, or their "Deep Mixing" specialty divisions, tend to be smaller, and do not participate in the type of structured trade associations seemingly obligatory in Japan.

The FHWA Report (2000) report located a total of 24 different methods described in the technical literature. They, however, can be categorized in a newly developed classification format (Figure 3) based on the following fundamental operational characteristics:

- The method of introducing the "binder" into the soil: wet (i.e., pumped in slurry or grout form, or blown in pneumatically in dry form). Classification is therefore $\mathrm{W}$ or $\mathrm{D}$.

- The method used to penetrate the soil and/or mix the agent: purely by rotary methods $(\mathrm{R})$ with the binder at relatively low pressure, or by a rotary method aided by jets of fluid grout at high pressure (J). (Note: Conventional jet grouting, which does not rely on any rotational mechanical mixing to create the treated mass, is not a DMM technology.)

- $\quad$ The location, or vertical distance over which mixing occurs in the soil - in some systems, the mixing is conducted only at the distal end of the shaft (or within one column diameter from that end), while in the other systems mixing occurs along all, or a significant portion, of the drill shaft. Classification is therefore $\mathrm{E}$ or $\mathrm{S}$.

With three bases for differentiation, each with two options, there are theoretically eight different classification groups. However, in practice, there are only four groups since wet grout, jetted shaft mixing (WJS) and dry binder, rotary, shaft mixing (DRS) do not exist, and no jetting with dry binder (DJS or DJE) has been developed. Full details of each method are provided in the FHWA study, Volumes 1 and 2 (2000).

\subsection{DMM Implementation}

Firstly, a common technical goal is to provide a uniformly treated mass, with no lumps of soil or binder, a uniform moisture content, and a uniform distribution of binder throughout the mass (Taki and Bell, 1997). This requires

- $\quad$ a thorough and uniform mixing of the soil and binder throughout the designated treatment area;

- $\quad$ appropriate water/cement ratio (where applicable); and 
- appropriate grout injection ratio (i.e., volume of grout/volume of soil to be treated) and cement factor. This, in turn, requires close coordination between drill penetration/ withdrawal rates, and the rate of grout injection.

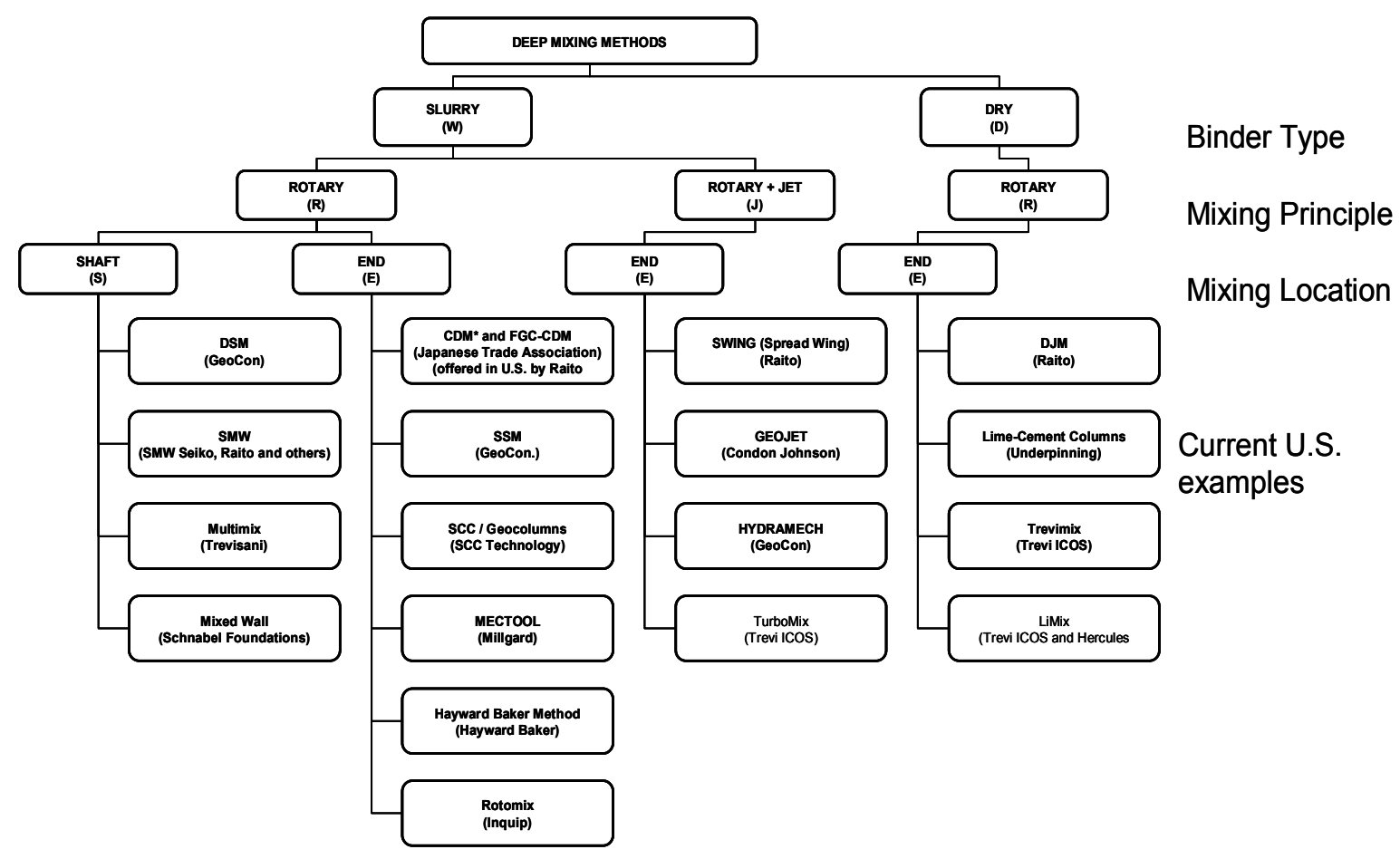

Figure 3. Classification of Deep Mixing Methods based on "binder" (Wet/Dry); penetration/mixing principle (Rotary/Jet); and location of mixing action (Shaft/End).

Secondly, although the various DMM techniques as pioneered in Japan, Scandinavia, the United States and Western Europe are clearly part of the same family and similar in overall concept, there are major and significant regional and procedural variations. For example, those methods and techniques (WRS, WRE, WJE) that use wet binder typically are designed to produce unconfined compressive strengths exceeding 1 $\mathrm{MPa}$. An exception is the FGC-CDM system where lower strengths are deliberately engineered. In contrast, DRE columns in Japan usually have a minimum strength goal of $0.5 \mathrm{MPa}$, while similar types of columns in Scandinavia typically only need to observe a $0.15 \mathrm{MPa}$ minimum criterion. Such differences in strength naturally generate corresponding differences in the relative stiffness of treated soil masses (as in block ground treatment applications) and composite soil/treated soil systems (as in in situ reinforcement applications). Furthermore, treated soils in Scandinavia using the DRE principle are often regarded as providing vertical drainage, while soils treated by other methods in other countries are usually regarded as being relatively impermeable. 
Thirdly, there are important considerations related to the sampling and testing of treated soil. Terashi (1997) summarized the factors influencing the strength of treated soil (Table 1). With respect to temperature, this is related to the size of the treated soil mass, as well as the quantity of binder introduced. In laboratory testing, there is no way to vary and simulate factors III and IV from Table 1, except for the amount of binder and the curing time. Laboratory testing therefore standardizes these factors, with the result that the strength data obtained during testing are "not a precise prediction," but only an "index" of the actual strength. Likely field strengths can then be estimated using empirical relationships established from previous projects, as noted in Section 4.4.1 below.

In general, the following commonalities can be established:

- The development of new methods, refinement of existing methods, and researches into alternative methods are continually underway.

- The materials injected are tailored to the method used, their local availability, the ground to be treated, and the desired or intended result. Generally, for the methods using a fluid grout, the constituents include cement, water, bentonite, flyash, occasionally gypsum, and various additives. Water/cement ratios typically range from less than 1 to greater than 2, although the actual in-place w/c ratio will depend on any "predrilling" activities with water or other fluids and the permeability of the soil. Most recently, dispersants have been considered, both to break down cohesive soils, and also to render more efficient the grout injected. For dry injection methods, cement and/or unslaked lime are the prime materials used.

Table 1. Factors affecting the strength increase of treated soil (Terashi, 1997)

\begin{tabular}{|c|c|c|}
\hline I & $\begin{array}{l}\text { Characteristics of hardening } \\
\text { agent }\end{array}$ & $\begin{array}{l}\text { 1. Type of hardening agent } \\
\text { 2. Quality } \\
\text { 3. Mixing water and additives }\end{array}$ \\
\hline II & $\begin{array}{l}\text { Characteristics and conditions } \\
\text { of soil (especially important } \\
\text { for clays) }\end{array}$ & $\begin{array}{l}\text { 1. Physical chemical and mineralogical properties of } \\
\text { soil } \\
\text { 2. Organic content } \\
\text { 3. pH of pore water } \\
\text { 4. Water content }\end{array}$ \\
\hline III & Mixing conditions & $\begin{array}{l}\text { 1. Degree of mixing } \\
\text { 2. Timing of mixing/re-mixing } \\
\text { 3. Quality of hardening agent }\end{array}$ \\
\hline IV & Curing conditions & $\begin{array}{l}\text { 1. Temperature } \\
\text { 2. Curing time } \\
\text { 3. Humidity } \\
\text { 4. Wetting and drying/freezing and thawing, etc. }\end{array}$ \\
\hline
\end{tabular}

- For wet methods (mechanically simpler and therefore advantageous in more remote geographic locations), the cement injected is typically in the range of 100 to $500 \mathrm{~kg} / \mathrm{m}^{3}$ of soil to be treated. The ratio of volume of fluid grout injected to soil mass treated is typically about 20 to $40 \%$. (A lower injection ratio is preferable, to minimize cement usage and spoil.) 
- For dry methods (in soils of 40 to more than $200 \%$ moisture content), typically 100 to $300 \mathrm{~kg}$ of dry materials per cubic meter of treated soil are used, providing strengths depending very much on soil type, with minimal spoil or heave potential.

- $\quad$ Treated soil properties (recalling that cohesive soils require more cement to give equivalent strengths than cohesionless soils) are usually in the ranges shown in Table 2. It must be remembered that techniques can be developed to specifically provide higher (or lower) strengths or lower permeabilities, and thus the figures cited in Table 2 are gross ranges only.

- There is a dearth of information on drained shear strengths of treated soils, especially when compared to the abundance of data from unconfined compressive testing. Such drained data are valuable for use on projects with long anticipated or required useful lives (e.g., 100-year flood applications).

Table 2. Typical data on soil treated by deep mixing.

\begin{tabular}{|c|c|}
\hline \multicolumn{2}{|r|}{ WET METHODS } \\
\hline PROPERTY & TYPICAL RANGE \\
\hline U.C.S. (typically at 28 days) & $\begin{array}{ll}0.2-5.0 \mathrm{MPa} & (0.5-5 \mathrm{MPa} \text { in granular soils }) \\
& (0.2-2 \mathrm{MPa} \text { in cohesives })\end{array}$ \\
\hline $\mathrm{K}$ & $1 \times 10^{-6}$ to $1 \times 10^{-9} \mathrm{~m} / \mathrm{s}$ (lower if bentonite is used) \\
\hline $\mathrm{E}_{50}$ & $\begin{array}{l}350 \text { to } 1000 \text { times U.C.S. for lab samples and } \\
150 \text { to } 500 \text { times U.C.S. for field samples }\end{array}$ \\
\hline $\begin{array}{l}\text { Shear strength (direct shear, no } \\
\text { normal stress) }\end{array}$ & $\begin{array}{l}40 \text { to } 50 \% \text { of U.C.S. at U.C.S. values }<1 \mathrm{MPa} \text {, but this ratio } \\
\text { decreases gradually as U.C.S. increases. }\end{array}$ \\
\hline Tensile strength & Typically 8 - 14\% U.C.S. \\
\hline 28-day U.C.S. & $\begin{array}{l}1.4 \text { to } 1.5 \text { times the } 7 \text {-day strength for silts and clays. } 2 \text { times } \\
\text { the } 7 \text {-day strength for sands }\end{array}$ \\
\hline 60-day U.C.S. & $\begin{array}{l}1.5 \text { times the } 28 \text {-day U.C.S., while the ratio of } 15 \text {-year U.C.S. } \\
\text { to } 60 \text {-day U.C.S. may be as high as } 3: 1 \text {. In general, grouts } \\
\text { with high w/c ratios have lower long-term strength gain } \\
\text { beyond } 28 \text { days. }\end{array}$ \\
\hline \multicolumn{2}{|r|}{ DRY METHODS } \\
\hline Undrained shear strength, $\mathrm{c}_{\mathrm{u}}$ & 10 to $50 \mathrm{x} \mathrm{c}_{\mathrm{u}}$ of soil $(150$ to $1000 \mathrm{kPa})$ \\
\hline Youngs Modulus & $\begin{array}{l}50 \text { to } 200 \times \mathrm{x} \mathrm{c}_{\mathrm{u}} \\
50 \text { to } 200 \times \mathrm{xq}_{\mathrm{u}} \text { of treated soil (cement only) }\end{array}$ \\
\hline Strain at failure & $<2 \%$ \\
\hline $\begin{array}{l}\text { Permeability (lime cement) } \\
\text { Permeability (lime) }\end{array}$ & $\begin{array}{l}\text { About the same as for in situ soils } \\
\text { Increases } 100 \text { to } 1000 \text { times }\end{array}$ \\
\hline
\end{tabular}




\section{QA/QC and Verification}

\subsection{Construction Process Controls}

Volume 3 of the FHWA study (2001) identified three distinct levels of sophistication in measuring, recording, displaying, and processing data:

Level 1: the most basic, where batching and injection parameters are monitored by simple instrumentation and displayed on digital or analog gages. The drilling operator typically determines changes to these parameters based on his evaluation of progress.

Level 2: parameters are controlled by computer, preset to provide a preselected volume ratio and cement factor. Data are automatically measured, recorded, and displayed, providing visual confirmation to the driller that they fall within the acceptable range. If not, manual adjustment can be made. Full construction records are automatically generated for each column. Spot checks are made of fluid slurry properties, as is the case for all levels. An excellent description for the CDM method is provided by Yano et al. (1996).

Level 3: a microprocessor senses frequently rpm, penetration rate, torque, thrust, slurry density, pressure, and injection rate. The computer reacts to changing ground conditions and automatically adjusts injection pressures to ensure specific treated soil parameters are provided for each stratum. The process is halted automatically if these projected soil parameters are unlikely to meet present limits or if penetration is frustrated by the ground conditions.

Regarding future developments, advances in computer technology will be leveraged to promote uniformly high quality mixing, and simplify daily report preparation and similar administrative tasks. In particular, the focus is on automatically controlling slurry discharge rates with depth; automatic confirmation of the bearing layer; facilitating the duties of the operators; and tracking in situ characteristics of the treated soil.

\subsection{Design Processes}

Based on the mass of experimental data available on the properties of treated soil, performance prediction models can be established and optimized, as shown in Figure 4: a standard conceptual flow chart for determining and achieving target treated soil strengths.

\subsection{Preproduction Field Tests}

Regardless of the level of expertise of the Contractor, and/or the general level of understanding of the particular site conditions, some type of pre-production test program is highly advisable, if not essential. Such a program affords the opportunity for the Contractor to demonstrate that the specified performance criteria, tolerances, and engineering properties can be met, even if two or more iterations have to be

made. Once these criteria have been achieved, then the production parameters can be 
selected logically and only modified if there are obvious changes in the soil, or in the project scope.

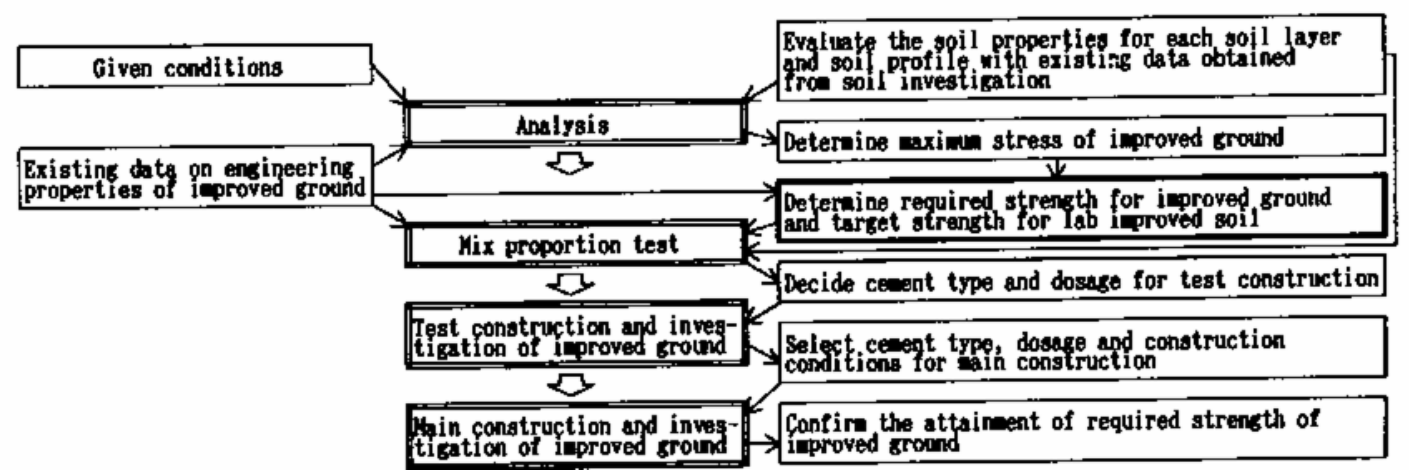

Figure 4. Flow chart of work involved to determine and achieve required strength of improved ground (Saitoh et al., 1996).

Such programs require the scope of the testing to be clearly defined, together with the acceptance criteria for every aspect. Testing and sampling is usually more rigorous than in the subsequent production phase. Test programs should also be a demonstration of the efficiency of the quality assurance/quality control and verification processes themselves.

\subsection{Verification Methods for Treated Ground}

The properties of treated ground are predicted and/or verified by the following broad groups of tests:

- Laboratory testing of laboratory samples (before construction).

- Wet grab sampling of fluid in situ material (during construction).

- Coring of hardened in situ material (after construction).

- $\quad$ Exposure and cutting of block samples (after construction).

- Miscellaneous methods, including geophysical testing (during and after construction).

It is reiterated that these properties are influenced in detail by many interactive factors, including soil type, amount and type of binder, water cement ratio, degree of mixing, curing conditions, environment, and age, although the soil characteristics themselves seem to be the most sensitive determinant of variations in strength. It should also be noted that the quality and accuracy of the data so obtained may be influenced by the nature of the test.

\subsubsection{Laboratory Testing}

Such testing is a valuable basis for confirming basic design assumptions, and for demonstrating the effect and impact of the various (remolded) materials used (both artificial and natural). It is also clearly useful in establishing base-line parameters, 
and for investigating in a controlled fashion the relationships between the various strength parameters and construction variables. With respect to temperature, this is related to the size of the treated soil mass, as well as the quantity of binder introduced. As noted in Section 3.2 above, data from laboratory testing programs provide "not a precise prediction," but only an "index" of the actual strength. Like field strengths can then be estimated using empirical relationships from previous projects, and by using engineering judgment. Various authors (Kamon, 1996; Kawasaki et al., 1996; Taki and Bell, 1998) have found field core strengths to be 20 to $80 \%$ those of laboratory specimens (typical range 50 to $70 \%$ ), with a far wider scatter of data.

\subsubsection{Wet Grab Sampling}

This is a cheap and popular method, particularly in the United States. Given the variation in the treated soil itself, and the sampling and curing process, a very wide scatter of data may be anticipated, with mean values perhaps as low as $50 \%$ of those obtained by coring (Taki and Yang, 1991).

\subsubsection{Coring}

Given that coring is an energetic, localized, and invasive technique, even when conducted with the best equipment, skill, and methods (the triple tube core barrel is widely recommended), it is notable that most contractors cite core samples as their prime source of data on treated ground properties in general, and unconfined compressive strength in particular. The expertise of Japanese specialists is especially high, routinely providing core recoveries of $95 \%$ from treated sandy soil and $90 \%$ from treated cohesives. Developments continue in coring technology (e.g., Sugawara et al., 1996). The use of triaxial as opposed to unconfined uniaxial testing will generally yield higher and more consistent data.

\subsubsection{Exposure and Block Sampling}

The opportunity to expose the treated ground allows all parties to observe column shape, homogeneity, diameter, nature of overlap and so on. It also permits samples to be taken with different shapes, sizes and orientations from those that can be obtained by vertical coring. The value of this kind of testing is underlined when it is recalled that important technical goals of any DMM operation are to provide a uniformly treated mass, with minimal lumps of soil or binder, a uniform moisture content, and a uniform distribution of binder throughout the mass. Exposed treated soil can be sprayed with phenolphthalein solution to indicate the presence of cement in the mass.

Single columns can be fully exposed, and even extracted, while multiple columns can be installed in a circular shaft, or box, arrangement to allow a selfsupporting excavation to be completed.

Again, the major drawbacks to such exercises are principally cost, time, and site logistics, but on certain projects of critical size, complexity and significance, exposure is a vital element in verification, both as a pre-production measure, but also 
as a special demonstration during construction. Burke (1998) is of the opinion that the most efficient method of evaluation is to drill a shaft into overlapping columns to allow visual observation of integrity, homogeneity and sampling of the mixed soils, and therefore to put into perspective any apparent anomalies identified by coring.

\subsubsection{Modified Geophysical Testing Methods}

Practitioners in Japan in particular are researching the use of existing geophysical techniques as means of assessing column strength, integrity, and homogeneity. Broadly, each can be described as "promising," having provided reasonable correlation with data from cores, but it does not seem that any geophysical method is used routinely. Types most frequently cited are

- $\quad$ Shear Wave Seismic

- $\quad$ Borehole Resistivity Profiling

- Low strain sonic integrity testing/borehole sonar

An excellent overview was provided by Hosoya et al. (1996).

\subsubsection{Modified Geotechnical Testing Methods}

Especially in the Nordic countries where column strengths are relatively low, it is common to adapt existing geotechnical testing techniques to illustrate primarily undrained shear strength. Virtually all routine testing on installed columns in the Nordic countries is carried out by some form of penetrometer testing. Brief details are shown in Table 3; note that each method has its own advantages and disadvantages.

\section{Final Remarks}

DMM is an extremely valuable, competitive, and useful ground engineering technology if applied correctly, designed properly, constructed efficiently, and restricted sensibly to the natural restraints of soil conditions and equipment capability. Despite its market potential, it remains a relatively costly technology for contractors to develop or acquire, and so the number of potential competitors, within the current domestic structure, will remain correspondingly low.

Following this logic, we may therefore conclude that among the geotechnical community in the United States, DMM may well become a commodity - such are its multi-faceted attractions - but a product that can be provided by only a relatively small number of producers. A close comparison with the circumstances of the petroleum production and distribution industry can be drawn. However, practitioners in DMM hope that the reserves of the DMM technology are not finite - as is the case with petroleum industry! 
Table 3. Advantages and disadvantages of modified geotechnical testing methods.

\begin{tabular}{|c|c|c|}
\hline METHOD & $\begin{array}{l}\text { RESEARCHING } \\
\text { COUNTRIES }\end{array}$ & Notes \\
\hline $\begin{array}{l}\text { Conventional } \\
\text { Column Penetration } \\
\text { (KPS) }\end{array}$ & Nordic countries & $\begin{array}{l}\text { Used since } 1980 \text { in columns of } \mathrm{s}_{\mathrm{u}} \text { less than } 200 \text { to } \\
300 \mathrm{kPa} \text {. } \\
\text { Depth limit } 6 \text { to } 8 \mathrm{~m} \text {, aided by pre-drilling. }\end{array}$ \\
\hline $\begin{array}{c}\text { Inverted Column } \\
\text { Penetrometer (FOPS) }\end{array}$ & Nordic countries & $\begin{array}{l}\text { Used in Sweden since early } 1990 \text { s for strengths up to } 600 \\
\text { to } 800 \mathrm{kPa} \text { and to depths of } 20 \mathrm{~m} \text {. }\end{array}$ \\
\hline KTH Penetrometer & Sweden & New simple development, of promise. \\
\hline Pressuremeter & Sweden/U.S. & $\begin{array}{l}\text { Accurate test, especially for stronger columns, being } \\
\text { promoted. }\end{array}$ \\
\hline $\begin{array}{c}\text { Dynamic } \\
\text { Penetrometer }\end{array}$ & France/U.K. & $\begin{array}{l}\text { Being used commercially in conjunction with Colmix } \\
\text { system. }\end{array}$ \\
\hline $\begin{array}{l}\text { Static/Dynamic } \\
\text { Penetrometer }\end{array}$ & Finland/Sweden & Developed in 1980s but not as accurate as CPT. \\
\hline $\begin{array}{c}\text { Standard Penetration } \\
\text { Test } \\
\end{array}$ & Japan & Widespread, simple test, well known. \\
\hline $\begin{array}{l}\text { Cone Penetrometer } \\
\text { (CPT) }\end{array}$ & $\begin{array}{l}\text { Norway and } \\
\text { Finland (since } \\
\text { 1970s) less in } \\
\text { Sweden }\end{array}$ & $\begin{array}{l}\text { Despite systematic problems, can provide data in } \\
\text { columns of } \mathrm{c}_{\mathrm{u}} \text { up to } 1000 \mathrm{kPa}, 20 \mathrm{~m} \text { depth. }\end{array}$ \\
\hline Modified Vane Test & Norway & $\begin{array}{l}\text { Under development for } \mathrm{c}_{\mathrm{u}} \text { less than } 200 \mathrm{kPa} \text { but use } \\
\text { decreasing with use of CPT in } 1990 \mathrm{~s} \text {. }\end{array}$ \\
\hline Tube Sampler & Norway & $\begin{array}{l}\text { Promising development but gives low strengths in } \\
\text { heterogeneous columns. }\end{array}$ \\
\hline Screw Plate Test & Nordic Countries & $\begin{array}{l}\text { Developed in early } 1970 \text { s and is a very precise but } \\
\text { expensive test. }\end{array}$ \\
\hline $\begin{array}{l}\text { Measurement While } \\
\text { Drilling (MWD) }\end{array}$ & Japan, Finland & $\begin{array}{l}\text { Good experimental results achieved in stronger columns } \\
\text { through real-time monitoring of drilling parameters. }\end{array}$ \\
\hline
\end{tabular}

\section{References}

Burke, G. (1998). "Single Axis Tooling Method." Presented at the University of Wisconsin Milwaukee Short Course on Deep Mixing Methods, Milwaukee, WI, August 27-28.

Das, P.K., J.J.G. Maswoswe, and E.Y.P. Yin. (1998). "Pre-Construction Aspects of Deep Soil-Cement Mixing for CA/T Project." Soil Improvement for Big Digs. Proceedings of Sessions of Geo-Congress 98, American Society of Civil Engineers, Geotechnical Special Publication No. 81, Boston, MA, October 18-21, pp. 122-134.

Federal Highway Administration. (2000). "An introduction to the deep mixing method as used in geotechnical applications." Prepared by Geosystems, L.P., Document No. FHWA-RD-99-138, March, 143 p.

Federal Highway Administration. (2000). "Supplemental reference appendices for an introduction to the deep mixing method as used in geotechnical applications." Prepared by Geosystems, L.P., Document No. FHWA-RD-99-144, 295 p. 
Federal Highway Administration. (2001). "An introduction to the deep mixing method as used in geotechnical applications: Verification and properties of treated soil.” Prepared by Geosystems, L.P., Document No. FHWA-RD-99-167, 434 p.

Hosoya, Y., T. Nasu, Y. Hibi, T. Ogino, Y. Kohata, and Y. Makihara. (1996). "JGS TC Report: An evaluation of the strength of soils improved by DMM." Grouting and Deep Mixing, Proceedings of IS-Tokyo'96, The Second International Conference on Ground Improvement Geosystems, Tokyo, Vol. 2, May 14-17, pp. 919-924.

Kamon, M. (1996). "Effect of grouting and DMM on big construction projects in Japan and the 1995 Hyogoken-Nambu Earthquake." Grouting and Deep Mixing, Proceedings of IS-Tokyo'96, The Second International Conference on Ground Improvement Geosystems, Tokyo, Vol. 2, May 14-17, pp. 807-823.

Kawasaki, K., H. Kotera, K. Nishida, and T. Murase. (1996). "Deep Mixing by Spreadable Wing Method.” Grouting and Deep Mixing, Proceedings of IS-Tokyo'96, The Second International Conference on Ground Improvement Geosystems, Tokyo, May 14-17, pp. 631-636.

Nicholson, P.J. and E.K. Chu. (1994). "Boston Central Artery Tunnel excavation support remediation by ground treatment." Presented at American Society of Civil Engineers Conference on Soil Structure Interaction and Environmental Issues, Hershey, PA, September 12-14.

Porbaha, A. (1998). "State of the art in deep mixing technology: part I, Basic concepts and overview", Ground Improvement, Journal of the International Society of Soil Mechanics and Geotechnical Engineering (TC-17), Thomas Telford, Vol. 2, No. 2, pp. 81-92.

Ryan C.R, and B.H. Jasperse. (1989). "Deep Soil Mixing at Jackson Lake Dam," Proceedings of the ASCE 1989 Foundation Engineering Congress, Foundation Engineering: Current Principles and Practices, Vol. 1 and 2, Evanston, Illinois, June 25-29, 1989, pp 354-367.

Saitoh, S., Y. Suzuki, S. Nishioka, and R. Okumura. (1996). "Required strength of cement improved ground." Grouting and Deep Mixing, Proceedings of IS-Tokyo'96, The Second International Conference on Ground Improvement Geosystems, Tokyo, May 14-17, pp. 557-562.

Sugawara, N., Y. Ito, and M. Kawai. (1996). "New core sampler with planet gear for investigating the cement-mixed ground." Grouting and Deep Mixing, Proceedings of IS-Tokyo'96, The Second International Conference on Ground Improvement Geosystems, Tokyo, May 14-17, pp. 653-658.

Taki, O., and R.A. Bell. (1998). "Soil-Cement Pile/Column - A system of deep mixing." Soil Improvement for Big Digs, Proceedings of Geo-Congress 98, American 
Society of Civil Engineers, Geotechnical Special Publication No. 81, Boston, MA, October 18-21, pp. 27-40.

Taki, O., and D.S. Yang (1991). "Soil-cement mixed wall technique." American Society of Civil Engineers, Proceedings, Geotechnical Engineering Congress, Denver, CO. pp. 298-309. Sugawara, N., Y. Ito, and M. Kawai (1996). "New core sampler with planet gear for investigating the cement-mixed ground." Grouting and Deep Mixing, Proceedings of IS-Tokyo'96, The Second International Conference on Ground Improvement Geosystems, Tokyo, Vol. 1, May 14-17, pp. 653-658.

Taki, O., and R.A. Bell. (1997). "Booklet on Soil-cement pile/column." SCC Technology, Inc., 23 p.

Terashi, M. (1997). "Deep mixing method - Brief state-of-the-art." 14th International Conference on Soil Mechanics and Foundation Engineering, 4 p.

Yang, D.S. (1997). "Chapter 2.5: Deep Mixing." In Situ Ground Improvement, Reinforcement and Treatment: A Twenty Year Update and a Vision for the 21st Century, Ground Reinforcement Committee, American Society of Civil Engineers, Geo-Institute Conference, Logan, UT, July 16-17. pp. 130-150.

Yano, S., S. Tokunga, M. Shima, and K. Kamimura. (1996). Grouting and Deep Mixing, Proceedings of IS-Tokyo '96, The Second International Conference on Ground Improvement Geosystems, Tokyo, May 14-17. pp. 681-687. 
Deep mixing, practice, classification, properties, QA/QC, verification, sampling 